\title{
Promoção de saúde: concepções, princípios e operacionalização
}

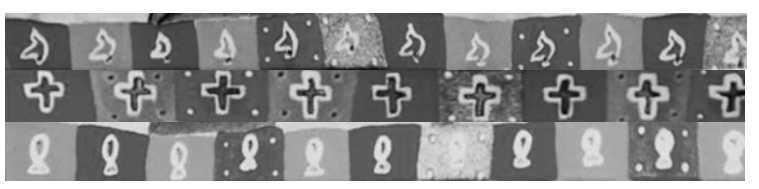

Juliana Lordello Sícoli ${ }^{1}$

Paulo Roberto do Nascimento ${ }^{2}$

SÍCOLI, J. L., NASCIMENTO, P. R. Health promotion: concepts, principles and practice, Interface - Comunic, Saúde, Educ, v.7, n.12, p.91-112, 2003.

Based on a bibliographical survey on the background, concepts and practices of the promotion of health, we found a gap in its methodological dimension, i.e., in experiences demonstrably coherent with the line of discourse of the promotion of health. The purpose of this study, therefore, was to describe the practice of the seven principles that characterize health promotion initiatives, as defined by the World Health Organization (holism, intersectoriality, empowerment, social participation, equity, multi-strategy actions and sustainability), taking into account five experiences of public management in different areas, obtained from the database of the Public Management and Citizenship Program of the Getúlio Vargas Foundation (EAPSP/FGV). Based on secondary data and the analysis of documents, we analyzed each one of the principles, its limits, possibilities and relevance for the promotion of health. The investigation led us to conclude that the principles mentioned are sufficiently universal and practicable to enable their identification in initiatives of a different nature and in which the health sector did not have a preponderant role. Raising issues for future studies, we look into the role that the health sector might take on as regards the policies of health promotion, such as it is conceived in this article, in order to have a greater impact on the conditions of daily life and the socioeconomic and environmental determinants of health, as the so-called "new promotion of health" preconizes.

KEY WORDS: Health promotion; public administration; social participation; intersectorial action.

A partir de levantamento bibliográfico acerca dos antecedentes, concepções e práticas de promoção de saúde, constatamos a lacuna existente em sua dimensão metodológica, isto é, em experiências que demonstrem ser coerentes com o discurso da promoção. O objetivo do estudo foi, então, descrever a possível operacionalização dos sete princípios caracterizadores das iniciativas de promoção de saúde definidos pela OMS (concepção holística, intersetorialidade, empoderamento, participação social, eqüidade, ações multi-estratégicas e sustentabilidade), a partir de cinco experiências de gestão pública de áreas diversas, recolhidas no banco de dados do Programa Gestão Pública e Cidadania (EAPSP/FGV). Com base em dados secundários e análise documental, analisamos cada um dos princípios, seus limites, possibilidades e relevância para a promoção. A investigação possibilitou concluir que os princípios mencionados são suficientemente universalizáveis e operacionalizáveis para permitir sua identificação em iniciativas de natureza diversa e nas quais o setor saúde não teve papel preponderante. Provocando questões para serem desenvolvidas em futuros estudos, indaga-se que papel poderia o setor saúde assumir nas políticas de promoção, tal como aqui concebida, a fim de impactar mais extensamente sobre as condições de vida cotidianas e os determinantes sócio-econômicos e ambientais da saúde, enfoque preconizado pela denominada "nova promoção de saúde".

PALAVRAS-CHAVE: Promoção de saúde; administração pública; participação social; ação intersetorial.

\footnotetext{
${ }_{1}^{1}$ Psicóloga, especialista em Saúde Coletiva, pesquisadora do Núcleo de Investigação em Serviços e Sistemas de Saúde (NISIS), Instituto de Saúde - SES-SP. <jusicoli@uol.com.br>

${ }^{2}$ Sociólogo, mestre em Saúde Pública, pesquisador do Núcleo de Investigação em Serviços e Sistemas de Saúde (NISIS), Instituto de Saúde - SES-SP. <pnasc@usp.br>

* Agradecemos a Cláudia Bógus pelas valiosas contribuições para o artigo; ao Núcleo ISIS pelas discussões, que certamente enriqueceram a pesquisa; a Jorge Kayano pelo incentivo, viabilização do acesso às experiências e leitura do material preliminar, e a Veronika Paulics, pela porta aberta aos documentos complementares no Instituto Polis.
} 
A promoção de saúde envolve, segundo Cerqueira (1997), duas dimensões: a conceitual - princípios, premissas e conceitos que sustentam o discurso da promoção de saúde - e a metodológica - que se refere às práticas, planos de ação, estratégias, formas de intervenção $e$ instrumental metodológico.

Apesar de ainda persistirem controvérsias na definição da promoção de saúde e confusões relativas a seus limites conceituais com a prevenção, desde a década de 1980 muitos autores vêm procurando desenvolver, clarificar e disseminar o discurso da promoção.

Contudo, como bem expressam Labonte (1996a), Cerqueira (1997) e Mello et al. (1998), o mesmo não pode ser dito quanto à dimensão metodológica da promoção. Apesar de os princípios estarem razoavelmente desenvolvidos, permanece a dificuldade de traduzi-los em práticas coerentes, a ponto de as raras práticas que privilegiam a "nova promoção de saúde" se encontrarem ainda dispersas e desarticuladas.

Preocupados com essa lacuna, analisamos experiências públicas de intervenção no nível local com o objetivo de descrever o modo pelo qual os sete princípios da promoção de saúde, definidos pela Organização Mundial de Saúde (OMS), se encontravam operacionalizados.

Elaboramos perguntas que nos conduziram durante a investigação: nas experiências estudadas, é possível identificar os princípios de promoção de saúde sedimentados nos documentos da OMS? Eles se mostraram operacionalizáveis? Esses princípios se consubstanciaram em práticas e políticas consistentes? De que forma os governos locais têm incorporado esses princípios em suas ações, programas e políticas?

Num contexto no qual está em evidência a busca de modelos de atenção à saúde que extrapolem a assistência médico-curativa, a promoção ganha destaque no campo da saúde pública. Ela resgata a concepção da saúde como produção social e busca desenvolver políticas públicas e ações de âmbito coletivo que extrapolem inclusive o enfoque de risco (campo da prevenção). Acreditamos que a discussão conceitual dos princípios da promoção de saúde aqui conduzida permite esclarecer sua definição e marcar sua distinção com relação às práticas preventivas. Ainda, o estudo da operacionalização de seus princípios contribui para o desenvolvimento da dimensão metodológica da promoção, permitindo avançar sua retórica.

\section{As origens e concepções da promoção de saúde}

Intimamente relacionada à vigilância à saúde e a um movimento de crítica à medicalização do setor, a promoção de saúde supõe uma concepção que não restrinja a saúde à ausência de doença, mas que seja capaz de atuar sobre seus determinantes. Incidindo sobre as condições de vida da população, extrapola a prestação de serviços clínico-assistenciais, supondo ações intersetoriais que envolvam a educação, o saneamento básico, a habitação, a renda, o trabalho, a alimentação, o meio ambiente, o acesso a bens $e$ serviços essenciais, o lazer, entre outros determinantes sociais da saúde.

A expressão "promoção de saúde" foi usada pela primeira vez em 1945 pelo canadense Henry Sigerist (Pereira et al., 2000). O médico historiador definiu quatro tarefas essenciais à Medicina: a promoção de saúde, a prevenção de doenças, o tratamento dos doentes e a reabilitação, afirmando 
que "la salud se promueve proporcionando condiciones de vida decentes, buenas condiciones de trabajo, educación, cultura física y descanso" (Sigerist apud Terris, 1992, p.38).

Terris (1992) ressalta que esta definição original da promoção, que enfatiza os "fatores gerais" de determinação da saúde, difere da concepção difundida pelo Informe Lalonde, de 1974, que privilegiou os "fatores particulares". Apesar disso, este relatório foi tido como um marco histórico no campo da Saúde Pública, por questionar oficialmente o impacto e o custo elevado dos cuidados médicos na saúde (Fundação Oswaldo Cruz, 2000). Lalonde destacara a limitação das ações centradas na assistência médica, insuficientes para atuar sobre os grupos de determinantes originais da saúde identificados por ele: os biológicos, os ambientais e os relacionados aos estilos de vida. Propusera, então, ampliar o campo de atuação da Saúde Pública, priorizando medidas preventivas e programas educativos que trabalhassem com mudanças comportamentais e de estilos de vida.

As repercussões do Relatório Lalonde podem ser identificadas na concepção orientadora das práticas de promoção de saúde ao longo da década de 1970 que, em sua maioria, tiveram seu foco restrito à modificação de hábitos, estilos de vida e comportamentos individuais não saudáveis, entre os quais o fumo, a obesidade, a promiscuidade sexual e o abuso de substâncias psicoativas. Tal abordagem centrava-se na prevenção de doenças crônico-degenerativas, problema prioritário nos países desenvolvidos.

A exemplo de outros intelectuais da Saúde Pública, Labonte (1996a) critica tal concepção de promoção de saúde relativa aos hábitos particulares, explicitando que se tratava de uma tentativa de contenção de custos da atenção às doenças. A prescrição de certos comportamentos individuais é criticada inclusive pela OMS (WHO, 1984), que afirma que seria um tipo de abordagem contrário aos princípios da promoção de saúde.

Cerqueira (1997), além de apontar o alcance limitado de tal enfoque, destaca a responsabilização individual e a culpabilização conseqüentes a essa abordagem. Ao considerar os indivíduos como exclusivos responsáveis pela saúde, as determinações sócio-políticas e econômicas ficam desatreladas, mascaradas; os governos e os formuladores de políticas são desresponsabilizados e a "culpa" pela situação de saúde recai no indivíduo. A autora prossegue a crítica ao destacar o custo elevado e os baixos resultados das campanhas de marketing social realizadas na década de 1980.

Entre os três principais "paradigmas" caracterizadores dos problemas de saúde apontados por Labonte (1996a), o terceiro enfoque indica uma retomada da concepção original de promoção defendida por Sigerist (apud Pereira et al., 2000). No primeiro grupo estariam os problemas "médicos", baseados na existência da doença e cujas ações são voltadas ao tratamento dos sintomas, à erradicação das doenças e prevenção ao agravamento do processo. O segundo agrupamento, referente aos problemas de Saúde

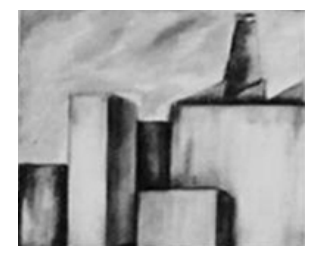
Pública, se encarregaria da prevenção, baseando-se na conduta e na promoção de comportamentos saudáveis, como a prevenção do hábito de fumar. O terceiro grupo responderia pelos problemas "socioambientais", visando a criação de entornos físicos e sociais que favoreçam a saúde e o 
bem-estar dos indivíduos. Suas ações destinam-se a mudanças sociais $e$ fundamentam-se no trabalho comunitário, envolvem medidas políticas $e$ não dependem somente dos profissionais da saúde.

Seguindo esta última perspectiva, o autor explicita claramente a determinação social da saúde e a necessidade de atuar sobre as condições sócio-políticas e econômicas a fim de promovê-la:

La pobreza, la precariedad del empleo y la contaminación desempeñan un papel cada vez mayor en los problemas de salud de nuestra sociedad y estamos empezando a comprender que ni los estilos de vida ni la epidemia actual de enfermidades crónicas pueden considerarse como hechos aislados y separados de nuestras estructuras políticas, sociales, económicas e industriales. (Labonte, 1996a, p.153)

Para Labonte (1996), esse terceiro enfoque corresponde à direção seguida pelos profissionais da Saúde Pública que se filiam à "nova promoção de saúde", dirigida aos fatores gerais, estruturais. São problemas característicos dessa ordem a pobreza, o desemprego, o estresse, as condições de trabalho e moradia precárias, o envelhecimento populacional, a violência, o isolamento social, entre outros.

Inspirada por estas novas perspectivas, a promoção de saúde ampliou seu marco referencial e assumiu a saúde como produção social, passando a valorizar mais intensamente determinantes sócio-econômicos, a instigar o compromisso político e a fomentar as transformações sociais.

O novo paradigma representa uma nova maneira de interpretar
as necessidades $e$ ações de saúde, não mais numa perspectiva
unicamente biológica, mecanicista, individual, específica, mas numa
perspectiva contextual, histórica, coletiva, ampla. Assim, de
uma postura voltada para controlar os fatores de risco e
comportamentos individuais, volta-se para eleger metas para a
ação política para a saúde, direcionadas ao coletivo. (Pereira
et al., 2000, p.4l. grifo nosso)

Neste contexto, a partir da década de 1980, a promoção de saúde passou a ganhar destaque no campo da Saúde Pública, tendo o conceito sido introduzido oficialmente pela OMS (WHO, 1984). Seu marco conceitual $e$ sua prática foram desenvolvidos predominantemente por Organizações Internacionais e por estudiosos da Europa Ocidental, Canadá e Estados Unidos (Cerqueira, 1997).

A Carta de Ottawa foi um marco importante. Inspirada pelos princípios da Declaração de Alma Ata (1978) e pela meta "Saúde para todos no ano 2000", a $1^{\text {a }}$ Conferência Internacional sobre Promoção de Saúde, realizada em 1986, "supone la síntese de los enfoques orientados hacia las causas generales y particulares de la promoción de la salud” (Terris, 1992, p.41). Declara a Carta que a promoção de saúde "consiste en proporcionar a los pueblos los medios necesarios para mejorar su salud y ejercer un mayor control sobre la misma" ${ }^{3}$ (OMS, 1996, p.367). Ao enfocar as condições

\footnotetext{
${ }^{3}$ A definição contida na tradução da Carta veiculada pelo Ministério da Saúde é significativamente diferente, dando destaque ao processo de empoderamento:

"Promoção de Saúde é o nome dado ao processo de capacitação da comunidade para atuar na melhoria da sua qualidade de vida e saúde, incluindo uma maior participação no controle deste processo".
} 
necessárias para tanto, afirma seu compromisso com a eqüidade:

La promoción de la salud se centra en alcanzar la equidad sanitaria. Su acción se dirige a reducir las diferencias en el estado actual de la salud $y$ a asegurar la igualdad de oportunidades y proporcionar los medios que permitan a toda la población desarrollar al máximo su salud potencial. (OMS, 1996, p.368)

A Carta explicita que a promoção está além do setor Saúde e enfatiza a atribuição da promoção de fazer com que todos os setores, inclusive os não diretamente implicados, assumam a Saúde como meta e compreendam as implicações de suas ações para a saúde da população:

Para promover la salud se debe ir más alla del mero cuidado de la misma. La salud ha de formar parte del orden del día de los responsables de la elaboración de los programas políticos, en todos los sectores $y$ a todos los niveles, con objetivo de hacerles tomar conciencia de las consecuencias que sus decisiones pueden tener para la salud y llevarles así a asumir la responsabilidad que tienen en este respecto. (OMS, 1996, p.368)

Assumindo a relação da saúde com a política, a economia, o meio ambiente $e$ os fatores sócio-culturais (além dos biológicos), atribui-se à promoção o dever de permitir que tais fatores sejam favoráveis à saúde.

Pressupondo a intersetorialidade, estabelece ao setor sanitário um papel mediador:

El sector sanitario no puede por sí mismo proporcionar las condiciones previas ni asegurar las perspectivas favorables para la salud $y$, lo que es más, la promoción de la salud exige la acción coordinada de todos los implicados: los gobiernos, los sectores sanitarios y otros sectores sociales y económicos, las organizaciones benéficas, las autoridades locales, la industria y los medios de comunicación (...) A los grupos sociales $y$ profisionales $y$ al personal sanitario les corresponde especialmente asumir la responsabilidad de actuar como mediadores entre los intereses antagónicos y a favor de la salud. (OMS, 1996, p.368)

A participação ativa da população é destacada como um meio essencial para operacionalizar a promoção de saúde:

La promoción de la salud radica en la participación efectiva y concreta de la comunidad en la fijación de prioridades, la toma de decisiones y la elaboración y puesta en marcha de estrategias de planificación para alcanzar un mejor nível de salud. La fuerza motriz de este proceso proviene del poder real de las comunidades, de la posesión y del control que tengan sobre sus propios empeños y destinos. (OMS, 1996, p.370) 
Dentre os campos de ação da promoção de saúde mencionados na Carta de Ottawa estão o estabelecimento de políticas públicas favoráveis à saúde, a criação de ambientes propícios, o fortalecimento da ação comunitária, o desenvolvimento de habilidades pessoais e a reorientação dos serviços sanitários.

A $2^{a}$ Conferência Internacional sobre Promoção de Saúde, realizada em Adelaide (Austrália) em 1988, enfatizou a elaboração de políticas públicas saudáveis, caracterizadas "pelo interesse e preocupação explícitos de todas as áreas das políticas públicas em relação à saúde e à eqüidade, e pelos compromissos com o impacto de tais políticas sobre a saúde da população" (Brasil, 2001, p.26). Na Declaração é afirmado que o principal propósito das políticas públicas saudáveis é a criação de ambientes físicos e sociais favoráveis à saúde.

A criação de tal entorno propício foi o foco da $3^{\text {a }}$ Conferência Internacional. Realizada em Sundsvall (Suíça), em 1991 - um ano antes da ECO-924 , o encontro firmou o compromisso das organizações do Sistema das Nações Unidas com o desenvolvimento sustentável e procurou explicitar e enfatizar a interdependência entre ambiente e saúde. A Declaração de Sundsvall preconiza que a criação de ambientes promotores de saúde deve sempre ser guiada pelo princípio da eqüidade.

A Declaração de Jacarta, fruto da $4^{a}$ Conferência Internacional sobre Promoção de Saúde, realizada na Indonésia, em 1997, reitera a concepção e os princípios referidos nas conferências anteriores e explicita que a "saúde é um direito humano fundamental e essencial para o desenvolvimento social e econômico" (Brasil, 2001, p.43).

Finalmente, a $5^{\text {a }}$ Conferência Mundial, realizada no México, em 2000, procurou avançar no desenvolvimento das prioridades da promoção de saúde para o século XXI identificadas em Jacarta e confirmadas pela Assembléia Mundial da Saúde de 1998: a) promover a responsabilidade social em matéria de saúde; b) ampliar a capacitação das comunidades e dos indivíduos; c) aumentar a "inversão" no desenvolvimento da saúde; d) assegurar a infra-estrutura necessária à promoção de saúde e fortalecer sua base científica; e) reorientar os sistemas e serviços de saúde.

Tendo a experiência brasileira em foco, a partir da $8^{\text {a }}$ Conferência Nacional de Saúde (1986) muito tem sido falado sobre promoção de saúde (Mello et al., 1998). A promoção é diretamente referida no Artigo 196 da Constituição de 1988 (Brasil, 1988). Na seção II, capítulo II do título VIII encontram-se as bases conceituais e organizativas do Sistema único de Saúde (SUS). Sob a ótica da saúde como fenômeno multideterminado e produzido socialmente, o Artigo 196 expressa uma importante conquista da Reforma Sanitária brasileira ao instituir a Saúde como direito de todos e dever do Estado "garantido mediante políticas sociais e econômicas que visem à redução do risco de doenças e de outros agravos e ao acesso universal e igualitário às ações e serviços para sua promoção, proteção $e$ recuperação" (Brasil, 1988, art. 196. grifo nosso).

Ao estimular o desenvolvimento e fortalecimento dos sistemas locais de saúde, a descentralização da saúde, uma das diretrizes do SUS prevista na Constituição de 1988, criou condições para ampliar a participação social

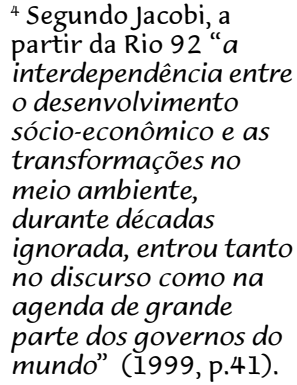


(outra diretriz do SUS) e fortalecer a democracia. É interessante associar estas duas diretrizes do SUS ao seguinte destaque feito por Mello (2000, p.1149): os "pressupostos básicos para viabilizar projetos em promoção de saúde continuam sendo a presença de governos democráticos com participação social efetiva e com determinação política de agendamento de propostas".

Como chamam a atenção Mello et al. (1998, p.584), apesar de a promoção estar assinalada também na Lei Orgânica da Saúde e encontrar ancoradouro nos caminhos da $9^{\text {a }}$ Conferência Nacional de Saúde, "políticas e ações não têm sido implementadas no cotidiano dos serviços, observandose com freqüencia o uso inadequado do termo, geralmente confundido com práticas de prevenção, educação e comunicação em saúde".

A constatação desses autores parece vir ao encontro da de Cerqueira (1997, p.17), que ressalta que "a pesar de numerosos esfuerzos por consolidar un enfoque democrático-participativo", a promoção de saúde continua sendo identificada com práticas individualistas e medicalizantes. "La promoción de la salud sigue vinculada con un enfoque de prevención de la enfermedad, es decir que la atención médica para curar, controlar y prevenir la enfermedad continúa siendo acción dominante" (Cerqueira, 1997, p.17).

A prerrogativa colocada por Mello (2000) pode ser associada à nova concepção de promoção defendida por Labonte (1996a), que busca, como já se viu, promover a participação da população $e$ fomentar a instituição de mecanismos democráticos para a tomada de decisão, implementação $e$ avaliação das políticas públicas. Assim seria impulsionado o compromisso real dos gestores com a justiça social, sendo, potencialmente, um instrumento promotor de mudanças na estrutura sócio-econômica $e$ política.

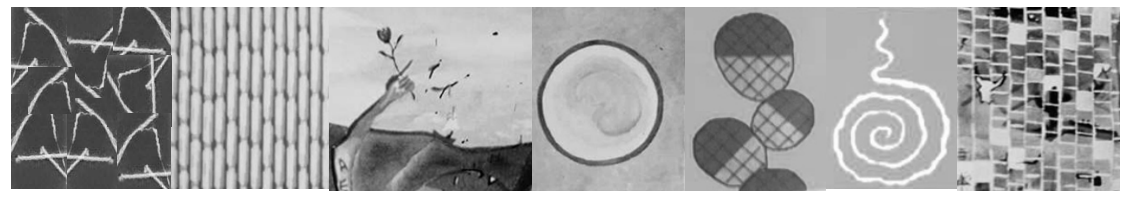

Definindo os sete princípios da promoção de saúde

A OMS caracteriza como iniciativas de promoção de saúde os programas, as políticas e as atividades planejadas e executadas de acordo com os seguintes princípios: concepção holística, intersetorialidade, empoderamento, participação social, eqüidade, ações multi-estratégicas e sustentabilidade (WHO, 1998).

A concepção holística determina que as iniciativas de promoção fomentem a saúde física, mental, social e espiritual (WHO, 1998) e pressupõe a compreensão ampliada de saúde assumida pela Organização. No documento produzido em 1984, a OMS (WHO, 1984, p.20) declara que " $a$ promoção de saúde envolve a população como um todo no contexto do seu dia-a-dia, ao invés de enfocar grupos de risco para doenças 
específicas" (tradução livre). Subentendida a saúde como fenômeno produzido socialmente, cabem ações de âmbito coletivo no cotidiano da população, extrapolando o campo específico da assistência médico-curativa. Este seria justamente o campo de ação da promoção, cuja concepção $e$ significado deveriam enfatizar a determinação social, econômica e ambiental mais do que puramente biológica ou mental da saúde.

Uma vez que tem suas ações e políticas dirigidas aos determinantes da saúde, como já visto, operacionalizar a promoção requer a cooperação entre os diferentes setores envolvidos e a articulação de suas ações: legislação, sistema tributário e medidas fiscais, educação, habitação, serviço social, cuidados primários em saúde, trabalho, alimentação, lazer, agricultura, transporte, planejamento urbano etc. Neste sentido, cabe destacar a responsabilidade do governo, tanto em nível local como nacional, de atuar de maneira a garantir que as condições totais, que estão além dos indivíduos ou grupos, sejam favoráveis à saúde (WHO, 1984). Segundo Luciano Junqueira (1997) a intersetorialidade é entendida como "articulação de saberes e experiências no planejamento, realização e avaliação de ações para alcançar efeito sinérgico em situações complexas visando ao desenvolvimento social ${ }^{5}$ e à inclusão social" (Junqueira apud Junqueira, 1998, p.84).

O empoderamento e a participação social são destacados como princípioschave, sendo a efetiva e concreta participação social estabelecida como objetivo essencial da promoção de saúde (WHO, 1984).

A participação é compreendida como o envolvimento dos atores diretamente interessados - membros da comunidade e organizações afins, formuladores de políticas, profissionais da saúde e de outros setores $e$ agências nacionais e internacionais - no processo de eleição de prioridades, tomada de decisões, implementação e avaliação das iniciativas (WHO, 1998).
${ }^{5} \mathrm{O}$ desenvolvimento social é orientado pelas necessidades dos cidadãos e pela eqüidade na atenção a tais necessidades visando a melhoria das condições de vida $e$ ampliação do exercício da cidadania.

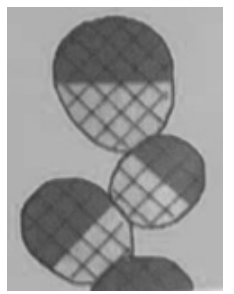

No desenvolvimento de políticas de promoção de saúde, deve haver contínua consulta, diálogo e troca de idéias entre indivíduos e grupos, tanto leigos como profissionais. Mecanismos políticos devem ser estabelecidos de forma a garantir oportunidades de expressão $e$ desenvolvimento do interesse público na saúde. (WHO, 1984, p.22. tradução livre)

É do âmbito da promoção investir na formação de cidadãos e trabalhar para a instituição de espaços verdadeiramente democráticos, especialmente no nível local, de modo a desenvolver políticas que partam dos problemas e necessidades de saúde identificados e que possam ser continuamente avaliadas e revisadas a partir delas.

A disseminação da informação e a educação são bases para a tomada de decisão e componentes importantes da promoção de saúde, preocupação que parece estar ligada ao princípio de empoderamento, entendido como processo de capacitação dos indivíduos e comunidades para assumirem maior controle sobre os fatores pessoais, sócio-econômicos e ambientais que afetam a saúde (WHO, 1998). Segundo Labonte (1996b) o termo refere-se ao processo de transformação da sensação de impotência, internalizada pelos

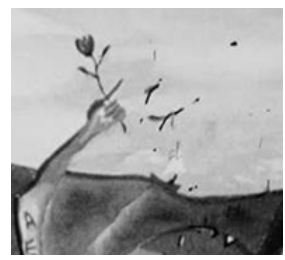




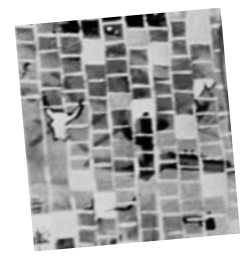

indivíduos perante as iniqüidades de poder. O primeiro passo na direção do empoderamento da comunidade "es devolverle el poder de definir" (Labonte, 1996a, p.155), seria fundamental à promoção de saúde comunitária, já que nela as comunidades são responsáveis pela definição e eleição de seus problemas e necessidades prioritárias.

Cabe aqui ressaltar que, ao implementar políticas de promoção de saúde, os princípios de empoderamento e participação não devem ser separados. A própria OMS (WHO, 1984) reconhece que garantir o acesso à informação $e$ ampliar o conhecimento em saúde sem aumentar a capacidade de controle e perspectivas de mudança apenas contribuem para gerar ansiedade e fomentar a sensação de impotência. É fundamental, portanto, vencer as barreiras que limitam o exercício da democracia e desenvolver sistemas flexíveis que reforcem a participação social e a cidadania, como preconizado pelas Conferências Internacionais realizadas, em especial as de Ottawa e Bogotá.

Como afirmado na Carta de Ottawa, a promoção tem como objetivo garantir o acesso universal à saúde e está afinada com o princípio de justiça social. "Alcançar a eqüidade consiste em eliminar as diferenças desnecessárias, evitáveis e injustas que restringem as oportunidades para se atingir o direito de bem-estar" (Brasil, 2001, p.40). "La prueba fundamental para saber si las diferencias en materia de salud son o no injustas parece depender en gran parte de si las personas escogen libremente la situación que produce una mala salud o si está fuera de su control" (Whitehead, 1990, p.9).

Segundo a OMS, para alcançar a eqüidade é preciso reorientar os serviços sanitários, visando ampliar o acesso, e criar ambientes de suporte, com políticas que viabilizem condições de vida favoráveis à saúde (WHO, 1984), priorizem "grupos desprivilegiados e vulneráveis" (Brasil, 2001, p.26), e revertam as desigualdades sociais instaladas.

Cabe ainda assinalar que não se trata de buscar suprimir por completo os diferenciais de saúde existentes na população, atingindo uma suposta igualdade sanitária, mas sim identificar diferenças injustas e evitáveis, remetendo à dimensão moral e ética subjacente ao princípio e à busca por realizar os direitos sociais. Como bem explicita Whitehead (1990, p.11)

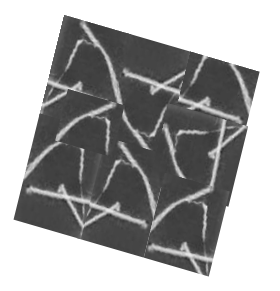

el objetivo de la política para conseguir la igualdad en materia de salud no es eliminar todas las diferencias sanitarias, de modo que todo mundo tenga el mismo nivel y calidad de servicios sanitarios, sino que reducir o eliminar las que resulten de factores que se consideran evitables $e$ injustos.

As ações multi-estratégicas pressupõem o envolvimento de diferentes disciplinas e dizem respeito à combinação de métodos e abordagens variadas, incluindo desenvolvimento de políticas, mudanças organizacionais, desenvolvimento comunitário, questões legislativas, educacionais e do âmbito da comunicação.

Finalmente, a sustentabilidade remete a um duplo significado: criar iniciativas que estejam de acordo com o princípio do desenvolvimento sustentável e garantir um processo duradouro e forte (Ziglio et al., 2000).

A continuidade das políticas de promoção de saúde é especialmente 
importante tendo em vista que se tratam de iniciativas de natureza complexa, envolvendo processos de transformação coletivos com impacto a médio e longo prazo. Ressalte-se que, segundo Jacobi (1999)

\section{Material e método}

Para responder as questões inicialmente propostas optamos por utilizar o banco de dados do "Programa Gestão Pública e Cidadania", originário de uma iniciativa conjunta da Fundação Getúlio Vargas de São Paulo (EAESP/ FGV) e da Fundação Ford. Tal banco demonstrou ser uma alternativa interessante na medida em que: 1 constatamos a dificuldade em encontrar descritores precisos que permitissem a identificação acurada de experiências de promoção de Saúde; 2 entre as experiências práticas auto-intituladas de "promoção de Saúde" deparamo-nos com a freqüente confusão quanto aos limites conceituais entre a prevenção e a promoção. Ao que parece, as experiências de promoção de saúde propriamente ditas encontram-se ainda dispersas e carecem de serem documentadas. Não estando suficientemente relatadas na bibliografia especializada, fomos buscá-las em outras fontes.

O banco de dados do "Programa Gestão Pública e Cidadania" está voltado a abranger e disseminar práticas e experiências públicas de governo nos âmbitos municipal, estadual ou regional, procurando premiar "o que está indo bem na administração pública" (EAESP/FGV, 2001). Reunindo práticas de áreas diversas (administração e governo, meio ambiente, serviços públicos, cidadania e direitos humanos, desenvolvimento econômico e social etc), para cada experiência inscrita nos ciclos de premiação anuais ${ }^{6}$ o banco de dados dispõe de informações constantes na ficha de inscrição e de um resumo do projeto. Sobre as cem iniciativas classificadas como semifinalistas há informações mais detalhadas, incluindo um questionário-padrão remetido pelo Programa aos responsáveis (material não disponibilizado por meio eletrônico e de acesso restrito). As experiências finalistas contam com um relatório de campo elaborado pelo técnico que fez a visita, o qual origina a publicação anual feita pela EAESP/FGV.

Adotamos os seguintes critérios para a seleção das experiências:

1) Ser "finalista" ou "destaque" (79 no total dos quatro anos), já que eram as que potencialmente dispunham do maior volume de informações;

2) Ser experiência de âmbito municipal ( 51 das 79), a fim de preservar o foco principal da promoção de saúde no nível local;

3) Abranger diversas áreas e temáticas, considerando o interesse prévio e as afinidades dos pesquisadores - idosos, questões ambientais, ações de

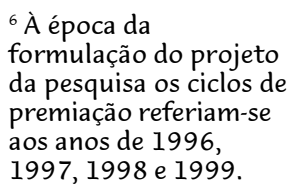


alcance coletivo e não apenas focalizadoras de grupos ou problemas específicos;

4) Contar com material adicional às publicações anuais da FGV?.

Três experiências da área de Saúde que preenchiam os pré-requisitos foram excluídas do estudo, pois nos relatos disponíveis identificamos um enfoque restrito à assistência à saúde ou à prevenção, aparentemente não alcançando ações orientadas pela promoção de saúde, o que reforça as observações de Mello (1998) e Terris (1996) sobre a falta de clareza que persiste quanto à concepção de promoção.

Deste modo, a investigação concentrou-se em cinco experiências-caso.

Quadro 1 - As cinco experiências-caso

\begin{tabular}{|c|c|c|c|}
\hline Título & Ciclo de premiação & Área de inscrição & Cldade/Estado \\
\hline Universalização e o ensino em Icapuí & 1996 & Educação & Icapuí - CE \\
\hline Modelo de gestão dos resíduos sólidos de BH & 1996 & Formas de gestão e planejamento & Belo Horizonte - MG \\
\hline $\begin{array}{c}\text { Projeto São Pedro: desenvolvimento urbano } \\
\text { integrado e preservação do manguezal }\end{array}$ & 1996 & $\begin{array}{c}\text { Preservação de acidentes em } \\
\text { áreas de risco }\end{array}$ & Vitória - ES \\
\hline Ação integrada nos bolsões de pobreza urbanos & 1997 & Habitação & Ipatinga - MG \\
\hline República Bem-Viver & 1998 & Idoso & Santos - SP \\
\hline
\end{tabular}

7 Os documentos

disponíveis no meio eletrônico $e$ as publicações anuais do Programa mostraram-se insuficientes para atingir os objetivos da pesquisa. Esse critério foi, então, viabilizado por meio de consulta ao Instituto Polis, parceiro do Programa. O material adicional englobou documentos relativos ao Programa Gestão Pública e Cidadania, questionários e relatórios enviados pelos responsáveis pelas iniciativas, outros do próprio Polis - como a publicação "Dicas" $e$ documentos arquivados no Centro de Documentação e Informação.
A pesquisa foi realizada a partir de dados secundários (já descritos), abordados pela técnica de análise documental. A descrição e análise das experiências-caso foi feita a partir de um roteiro de questões inspirado no modelo de questionário do Programa Gestão Pública e Cidadania (objetivo da iniciativa e principais metas; contexto e surgimento da demanda; público-alvo; funcionamento e gestão; articulação entre diferentes setores e esferas de governo; gasto orçamentário e fontes de recursos; trajetória e resultados das ações), e nas próprias definições dos sete princípios da promoção de saúde.

Inicialmente fizemos leituras do material publicado pela FGV, sendo produzida uma síntese para cada uma das cinco experiências.

Prosseguimos com a consulta ao material adicional disponível no Instituto Polis, sendo as informações complementares incorporadas às sínteses produzidas. Buscamos no meio eletrônico informações mais atualizadas sobre as iniciativas, posteriormente incorporadas a cada uma das sínteses.

\section{Discussão}

É interessante observar que as experiências investigadas são bastante distintas e ricas pela heterogeneidade. Envolvem municípios de quatro estados: Ceará, Minas Gerais, Espírito Santo e São Paulo; o porte populacional varia entre 16 mil e mais de dois milhões de habitantes; $e$ suas ações principais apresentaram focos distintos: idosos, educação, 
habitação, coleta e tratamento do lixo e recuperação do ecossistema. Também o tempo de existência dos programas e políticas é diverso, variando de cinco a 15 anos, assim como a procedência dos recursos humanos e financeiros - a Prefeitura está sempre presente, porém há também participação de recursos estaduais e federais, de grandes agências financiadoras internacionais e de entidades da sociedade civil sem fins lucrativos.

A seguir uma breve síntese de cada experiência $e$ a análise dos sete princípios, seguindo a ordem que julgamos mais pertinente à discussão articulada.

Icapuí, pequeno município do estado do Ceará, investe desde 1986 no desenvolvimento de um sistema educacional baseado no princípio de universalização do acesso ao ensino, promovendo a expansão e a qualificação da rede pública. Recentemente emancipado, o município registrava elevados índices de analfabetismo, carência de escolas e problemas como evasão escolar e repetência. Buscando reverter esse quadro, as sucessivas administrações municipais estabeleceram a educação como uma das prioridades de governo. Os resultados alcançados ao longo desses quinze anos fizeram com que a experiência ganhasse destaque no âmbito estadual, regional e até internacional.

Belo Horizonte, capital mineira, à semelhança de grandes centros urbanos, reconheceu no acúmulo do lixo um grave problema e desafio à gestão municipal. Produzindo grande volume de resíduos sólidos diariamente, teve que enfrentar amplamente a questão, desenvolvendo formas mais eficientes de coleta do lixo (incluindo a coleta seletiva), armazenamento e especialmente seu tratamento e destino final. O destaque fica por conta do convênio com os catadores e as melhores condições de trabalho viabilizadas aos garis. Assim, as metas de minimizar os impactos ambientais causados pela geração de resíduos sólidos e maximizar os benefícios sociais e econômicos com a otimização dos serviços parecem estar de fato sendo alcançadas.

A região de São Pedro, uma das mais pobres de Vitória, teve sua ocupação ampliada a partir da segunda metade da década de 1970, por conta dos fluxos migratórios à capital do Espírito Santo. A nova população ocupou irregular e desordenadamente o manguezal da baía nordeste de Vitória e passou a recorrer a formas precárias e quase sub-humanas para assegurar sua sobrevivência. Seguidas pressões da comunidade levaram os gestores municipais a se comprometerem com um projeto buscando melhorar as condições de vida locais (com destaque para a moradia) e preservar e recuperar o manguezal.

Ipatinga, município mineiro localizado na microrregião do Vale do Aço e com sua história vinculada à instalação da Usiminas, registrava amplo déficit habitacional e significativa desigualdade no acesso aos serviços e equipamentos urbanos. As pressões da população organizada levaram a prefeitura a firmar parceria com a Associação Habitacional de Ipatinga, buscando caminhos para promover o acesso à moradia (via mutirões auto-gestionários, regularização fundiária, além de controle do uso e ocupação do solo) e o desenvolvimento das comunidades por meio da implementação de "projetos sociais integrados".

Santos é uma das cidades brasileiras com maior índice de população idosa. A Baixada Santista conta inclusive com migração de idosos aposentados, atraídos pela busca de uma melhor qualidade de vida e pela oferta de equipamentos urbanos voltados à faixa etária. Contudo, o alto custo dos aluguéis e taxas de condomínio não raro frustra tais expectativas, levando a um aumento do número de idosos vivendo em cortiços, favelas, áreas de risco e assentamentos, quando não em asilos. Tal contexto impulsionou a organização de várias entidades de defesa dos direitos dos idosos e levou a prefeitura a desenvolver e priorizar programas sociais voltados a essa população. A República Bem-Viver, moradia coletiva inspirada nos moldes das repúblicas estudantis, representa uma experiência-piloto, a primeira do gênero no país. Permite assegurar o direito à moradia aos idosos de baixa renda, afastando-os da institucionalização nos moldes asilares e preservando sua independência e autonomia.

A partir da análise do material acumulado, pudemos apreender que a operacionalização dos princípios de promoção de saúde é viável. Os sete princípios, resguardadas as maiores e menores dificuldades de identificação, bem como as diferenças entre as experiências, foram contemplados pelas administrações municipais, mesmo sem necessariamente terem tal intencionalidade e clareza ou, ainda, sem terem em vista a promoção de saúde. 


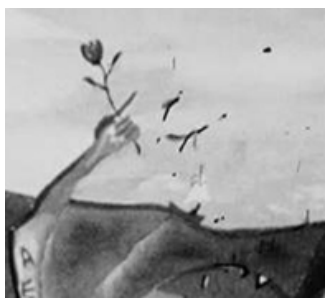

Cabe observar que a única experiência que mencionou diretamente a promoção parecia orientar-se por uma concepção preventivista, propondo ações educativas que não chegaram a ser detalhadas.

Passando o foco a cada um dos princípios, destaca-se que a maior dificuldade para a identificação foi o empoderamento, talvez por ser um conceito que remete, como compreende Labonte (1996), a um processo de transformação da impotência internalizada pelos indivíduos, tendo assim expressão sutil e indireta. Seria pertinente pensar que o empoderamento se concretizaria/materializaria por meio da participação social?

Assumido o empoderamento como processo de capacitação para impulsionar o controle social, dois relatos permitem inferir a orientação pelo princípio. Em Icapuí, extrapolando o Programa - recorrendo ao período anterior à emancipação municipal - é razoável supor que os treinamentos em saúde e lideranças comunitárias promovidos pela frente de ação social da Igreja Católica tenham constituído uma iniciativa voltada ao empoderamento. Já em Santos, a "capacitação" dos idosos parece ter ocorrido via inserção direta nas instâncias de participação da cidade (comissões e conferências), sugerindo que o aprendizado se deu por meio do processo sócio-político e do exercício democrático.

Tais análises sugerem que ao discutir a promoção o "princípio-chave" seja a participação ativa da população, tendo como pressuposto o processo de empoderamento, mesmo que a partir das vivências diretas nas instâncias participativas surjam lacunas na formação e no conhecimento dos atores que precisem ser superadas. Esta concepção difere da que vem sendo fomentada por muitos atores da área, os quais defendem o empoderamento como o mais essencial dos princípios da promoção, inclusive chegando a não explicitar sua fundamental articulação com a participação social e a reduzir a concepção de promoção a ele. Embora hoje o empoderamento compreenda uma perspectiva distinta da conscientização, havendo uma tentativa de incorporar os preceitos da educação popular e reconhecer o outro como ator, assumir este princípio como a parte mais essencial à promoção é preocupante, pois pode incorrer nos riscos de enfocar simplesmente a dimensão singular ou particular da mudança, sem atrelá-la ao processo estrutural maior, e de fomentar a responsabilização individual, desresponsabilizando o Estado, não articulando a capacitação com a participação ativa e cidadã que de fato permite impulsionar mudanças nos determinantes sócio-econômicos e ambientais da saúde.

Essencial para viabilizar a operacionalização da promoção de saúde, a participação pôde ser identificada em cada uma das cinco experiências, porém com amplitudes e extensões distintas. Foi percebida a dificuldade de assegurar que ela de fato ocorra em todo processo, desde a identificação de problemas/diagnóstico/análise de conjuntura, passando pela eleição de prioridades, estabelecimento de metas e planejamento das ações, sua implementação e, ainda, avaliação e redirecionamento. Nos cinco casos, assimilou-se a participação na implementação, planejamento das iniciativas $e$ seu desenho inicial, mas mostrou-se incipiente a participação nos processos de avaliação e redirecionamento das ações, uma possível lacuna que parece merecer maior atenção. 
É importante marcar a distinção entre participação comunitária $e$ participação popular, esta ligada ao exercício político de luta pelos direitos sociais, à "cidadania ativa", conforme termo usado por Amélia Cohn (2000, p.299). Parece-nos fundamental que a participação seja politizada, no sentido de permitir que a população de fato participe do processo de formulação e tomada de decisão acerca das políticas públicas da cidade. Marque-se a necessidade de fortalecer os canais de representação da sociedade, viabilizando o diálogo e a negociação com os múltiplos setores $e$ grupos sociais e ultrapassando as relações clientelistas, corporativistas e de cooptação. Novamente vale destacar ser fundamental o compromisso do Estado com este princípio e com os problemas sociais trazidos à tona por meio dele, sem o qual a cidadania ativa não se realiza plenamente:

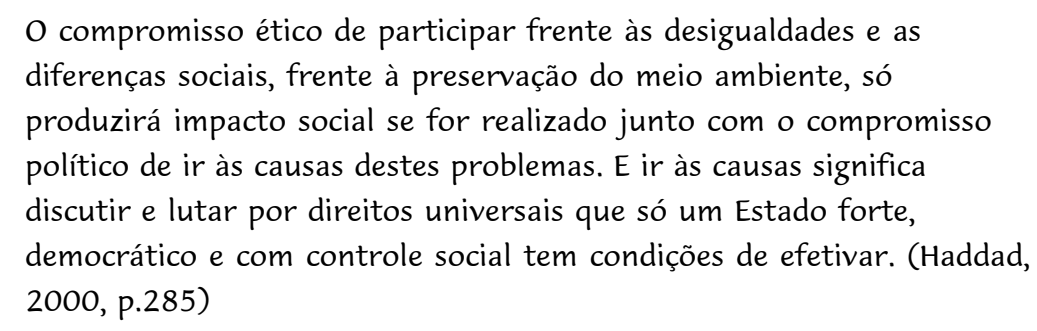

Buscando identificar o princípio de participação na perspectiva popular, procurou-se perceber o modo como as decisões foram tomadas, conhecer os mecanismos concretos e instâncias de participação existentes - tais como conselhos e fóruns, como os de discussão do Orçamento Participativo ${ }^{8}$, bem como a atenção dada pela administração aos canais de comunicação e diálogo $e$ a possibilidade de as políticas serem pactuadas e não traçadas

exclusivamente pelo Poder Executivo. Enfatize-se a importância de que a participação se estenda ao acompanhamento da destinação dos recursos financeiros, pressupondo sua transparência e aplicação orientada por critérios decididos conjuntamente, com comprometimento efetivo da administração pública e engajamento dos trabalhadores e população para sua deliberação. Nesse aspecto, merecem destaque as experiências de Ipatinga, Santos, Vitória e Icapuí, tanto pela permeabilidade às demandas populacionais, como pela efetiva ampliação do diálogo entre Estado e sociedade civil ao longo do processo, que inclusive chegaram a assegurar a vitalidade e continuidade de algumas delas.

De fato, como alertado por Mello (2000), a participação ativa ao longo do processo decisório foi possível nos locais em que a administração se voltava a uma gestão democrática, permeável às demandas e necessidades da população, e ainda onde já havia precedente de mobilização popular e organização da sociedade civil na luta por seus direitos, não tendo sido meramente um processo induzido pela gestão municipal. É importante destacar, a partir do ocorrido em Ipatinga, que movimentos ou associações podem ser intermediários interessantes para organizar as demandas da população, promovendo espaços de discussão coletivos, acompanhando o rumo das políticas e funcionando, inclusive, como instâncias que decidem o destino dos recursos, segundo critérios estabelecidos junto à população.

${ }^{8}$ Ver também Carvalho E Felgueiras, 2000. 
Vale registrar que no caso do princípio de participação, mais do que nos outros, o fato de utilizar dados secundários e relatos de visita implica uma perda significativa, já que é sabido que, mais do que a mera existência de instrumentos, o que determina o caráter e a extensão da participação é como ela se dá concretamente. Isto é, se é qualificada (acesso à informação, capacidade técnica e força política capaz de fazer frente ao poder público) $e$ se de fato delibera sobre os rumos das políticas. Dito de outro modo, conselhos, conferências e fóruns como o Orçamento Participativo, ainda que representem instrumentos instituídos com potencial para assumir força instituinte, estão longe de assegurar o exercício democrático, pois podem também ser manipulados e sofrer a pressão de lobbys que desvirtuem a proposta original dessas instâncias, servindo de meros legitimadores de decisões centralizadas, ou ainda não ter suas deliberações incorporadas pelo Poder Executivo. Esbarrando num limite do método adotado, este é um ponto que mereceria maior cuidado e aprofundamento numa próxima investigação.

A concepção holística é outro princípio cuja identificação exige a ampliação do foco da concepção de saúde para o modo como a intervenção foi pensada e efetivada. Desta forma, buscamos perceber se a iniciativa tinha o foco restrito a uma população ou um problema específico, descontextualizado de uma análise conjuntural $e$ incidindo sobre a dimensão singular, ou se, conforme nossa expectativa, tratava-se de uma intervenção sobre os determinantes gerais da saúde, capaz de impactar sobre as condições de vida cotidianas.

Marque-se aqui a distinção com relação às práticas voltadas ao fomento de ações preventivas, dirigidas a grupos ou fatores de risco, $e$ aquelas voltadas à difusão de determinados estilos de vida/hábitos individuais. Não se trata de promover ações individuais saudáveis e processos condutistas, como criticado pela própria OMS no documento de 1984, mas de desenvolver ações coletivas no cotidiano da população, tendo como ponto de partida a análise do contexto sócio-econômico e político e suas desigualdades. Nesta direção, acreditamos que os problemas desencadeadores de cada uma das iniciativas estudadas sejam bastante pertinentes: habitação (Ipatinga e Santos), educação (Icapuí), infraestrutura urbana e ações sócio-ambientais - tratamento adequado do lixo (Belo Horizonte) e recuperação do manguezal (Vitória). Vale ainda resgatar três dos campos de ação mencionados na Carta de Ottawa que acreditamos estar mais identificados com a chamada nova promoção de saúde: a elaboração de políticas públicas, a criação de ambientes favoráveis à saúde e o fortalecimento da participação da população.

Partindo de uma análise conjuntural e reconhecendo as enormes desigualdades sociais, a eqüidade (quarto princípio que analisamos) supõe uma ação que caminhe na direção de reduzi-las pela priorização de intervenções nos segmentos com piores condições de vida. Ao assumir uma concepção de promoção que enfatiza os determinantes sócio-ambientais $e$ econômicos da saúde, certamente o princípio da eqüidade deve ser 
norteador das ações. Sua apreensão foi possível pela identificação do públicoalvo ou do local privilegiado para intervenção pelos programas e políticas públicas desenvolvidos. Verificamos também se as ações realizadas contribuíam de fato para mudanças das condições de vida, tornando-as favoráveis à saúde e permitindo a efetivação de direitos sociais. Destaquemos os casos de Santos e Vitória.

Cabe aqui ampliar a compreensão do princípio de eqüidade, articulando-o à complexa discussão sobre as desigualdades sociais e o desenvolvimento econômico e social. Como aponta Prata (1994, p.388),

O conceito de desigualdade referencia a relação entre desenvolvimento e justiça social, estando relacionado com a distribuição de renda, educação, moradia, serviços (serviços de saúde, abastecimento de água e saneamento ambiental), acesso a emprego, a bens de consumo, à terra, bem como ao poder de decisão e de influência social.

Diferentemente do desenvolvimento almejado pela economia clássica, a concepção de desenvolvimento social não tem como foco o crescimento econômico, mas sim o "bem-estar social", pressupondo a justiça, a ética e os direitos sociais. O autor explicita, ainda, os limites de atuação do setor Saúde perante tal conjuntura:

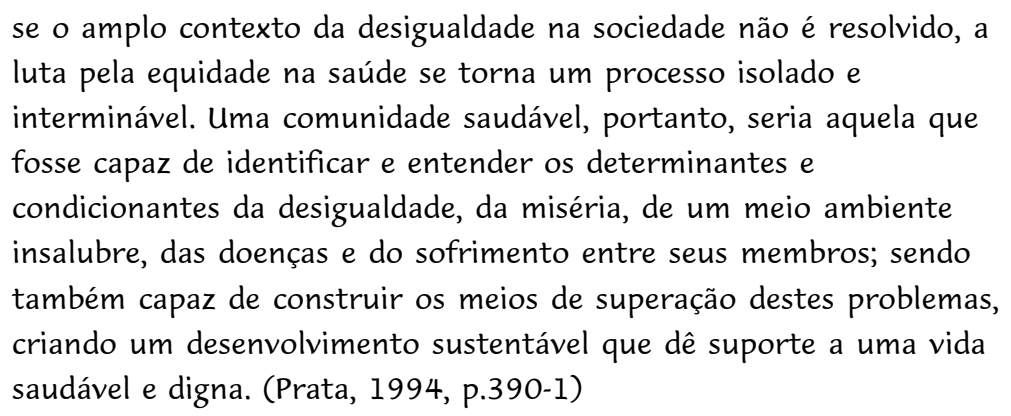

Tal ponto de vista nos remete a uma antiga, porém não resolvida, questão que perpassa o campo da Saúde Pública: o quanto a Saúde prescinde ou está condicionada ao desenvolvimento social. Sem dúvida foge ao âmbito deste projeto desenvolver tal discussão, porém acreditamos que vale apontá-la, já que tangencia a discussão central.

Retomando os princípios propriamente ditos, as ações multi-
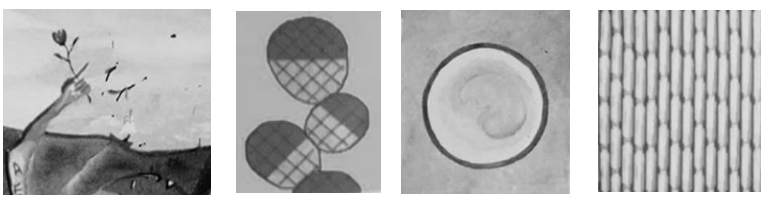
estratégicas pressupõem ações em diferentes frentes: desenvolvimento de políticas públicas, legislação, mudanças organizacionais, fortalecimento comunitário, educação e comunicação. O caráter operativo destas frentes permitiu que fossem facilmente identificadas em todas as iniciativas, o que se relaciona à necessidade de satisfazer a complexidade e abrangência dos problemas envolvidos (fenômenos complexos como a promoção de saúde exigem respostas complexas, de frentes variadas, capazes de atingir mais extensamente o problema). Uma questão permanece colocada: existe uma relação mais direta entre este princípio operativo e o princípio da intersetorialidade? Por vezes, ao analisar os relatos, pareceu-nos que as ações multi-estratégicas seriam a concretização de práticas orientadas pela intersetorialidade.

Ao ter como foco ações sobre os determinantes dos problemas de saúde e aquelas necessárias à redução das iniqüidades sociais, a operacionalização da promoção requer um trabalho com os múltiplos setores onde estes problemas e iniqüidades estão radicados, sendo, portanto a intersetorialidade um princípio essencial. Ele representa outro desafio para as políticas públicas, que apesar de reconhecerem sua importância, encontram enorme dificuldade para implementá-lo devido à persistência da lógica setorial e da fragmentação e desarticulação do modelo administrativo tradicional. Como dizem Junqueira e Inojosa (2001), as prioridades referemse a políticas particulares, definidas e realizadas vertical e paralelamente, ainda que para uma mesma população, um modelo de gestão que acaba por perder de vista a integralidade do indivíduo, as necessidades e direitos da população.

De acordo com Westphal e Ziglio ( $\mathrm{s} / \mathrm{d}$ ), a intersetorialidade exige uma

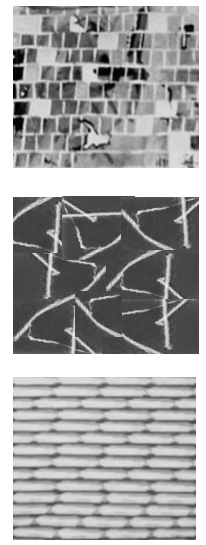
mudança radical nas práticas e na cultura organizacional da administração municipal, pressupondo superar a fragmentação na gestão das políticas públicas e os diferentes estágios de desenvolvimento nos quais encontramse os setores, especialmente quanto à descentralização das decisões. Como bem destacam Junqueira e Inojosa (2001), o necessário processo de mudança torna-se viável quando, além de um bom projeto e da vontade política do dirigente, propiciam-se negociações entre os diferentes atores sociais da arena política, sendo essencial a valorização do servidor público.

Mesmo quando a intersetorialidade é explicitamente tida como meta a ser atingida, a exemplo dos casos de Ipatinga e Vitória, as experiências estudadas evidenciaram as dificuldades de sua concretização em função das resistências apresentadas pelos diversos setores envolvidos. De difícil operacionalização, este princípio deve merecer atenção especial dos projetos que visam a promoção de saúde, até porque a própria lógica de financiamento dos projetos sociais (predominantemente setorial ou - ainda pior - restrita a programas específicos de determinados setores) tende a dificultar (quando não inviabilizar) sua operacionalização. Casos como Ipatinga, Santos e Vitória nos levam a questionar se os obstáculos envolvidos remetem a possibilidade de alcance do princípio a um segundo momento do projeto, quando já encontra alguma sustentação em determinada área/setor e consegue sensibilizar e articular outros setores, permitindo ampliar a extensão da iniciativa e dar conta do problema de 
SÍCOLI, J. L., NASCIMENTO, P. R.
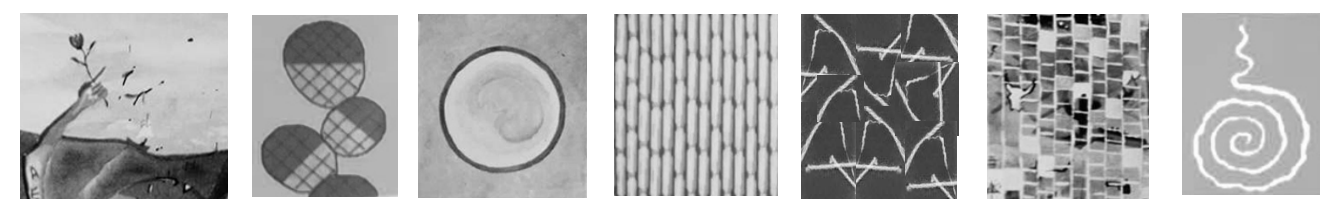

maneira mais efetiva.

A descontinuidade das políticas costuma ser outro obstáculo à operacionalização da intersetorialidade e aí se apresenta o princípio da sustentabilidade. A dupla perspectiva da sustentabilidade, isto é, aquela articulada ao desenvolvimento sustentável e a referida à continuidade das políticas, pôde ser apreendida a partir do estudo das experiências. $\mathrm{O}$ desenvolvimento sustentável pressupõe considerar a viabilidade econômica e ambiental das ações e iniciativas. Está ligado à busca de alteração do modelo predatório de desenvolvimento, à ampliação de práticas educativas e ao fortalecimento do sentimento de co-responsabilização e instituição de valores éticos. A orientação por este princípio parece mais clara nos projetos de Belo Horizonte e Vitória (São Pedro), tanto por conta do problema desencadeador, como pela forma de intervenção adotada.

A questão da continuidade das políticas procurou ser trabalhada em termos da continuidade administrativa (ainda que não necessariamente da gestão partidária), e da retroalimentação pela população, que, ao identificar respostas a demandas locais e reconhecer os impactos alcançados, assumiu o acompanhamento dos projetos e conseguiu assegurar sua vitalidade e não interrupção, com destaque para os casos de Icapuí e Santos. Problema freqüente nas políticas públicas, a descontinuidade está imbricada no insucesso de políticas que lidam com problemas complexos e que só têm impacto a médio e longo prazo. É interessante notar ainda que a continuidade nos casos estudados parece estar também relacionada ao fato de a experiência não ficar meramente circunscrita ao programa ou projeto específico, mas de estar articulada ao projeto político de desenvolvimento de ações públicas na cidade em questão.

O Quadro 2 sintetiza a identificação dos sete princípios de promoção de saúde em cada uma das cinco experiências estudadas.

Quadro 2 - As cinco experiências-caso e os princípios identificados

\begin{tabular}{|c|c|c|c|c|c|}
\hline Princípios & Icapuí & Belo Horizonte & São Pedro (Vitória) & Ipatinga & Santos \\
\hline Empoderamento & $\mathbf{x}$ & & & $\mathbf{x}$ \\
\hline Concepção holística & $\mathbf{x}$ & $\mathbf{x}$ & $\mathbf{x}$ & $\mathbf{x}$ & $\mathbf{x}$ \\
\hline Participação social & $\mathbf{x}$ & $\mathbf{x}$ & $\mathbf{x}$ & $\mathbf{x}$ & $\mathbf{x}$ \\
\hline Intersetorialidade & & & $\mathbf{x}$ & $\mathbf{x}$ \\
\hline Eqüidade & & & $\mathbf{x}$ & $\mathbf{x}$ & $\mathbf{x}$ \\
\hline Ações multi-estratégicas & $\mathbf{x}$ & $\mathbf{x}$ & $\mathbf{x}$ & $\mathbf{x}$ & $\mathbf{x}$ \\
\hline Sustentabilidade & $\mathbf{x}$ & $\mathbf{x}$ & $\mathbf{x}$ & $\mathbf{x}$ & $\mathbf{x}$ \\
\hline
\end{tabular}




\section{Considerações finais}

A primeira diz respeito aos limites do caminho metodológico adotado e, portanto, aos resultados aqui discutidos. Ao optarmos pela utilização de dados secundários e relatos das experiências com "olhos emprestados" de outrem que já portam uma elaboração das iniciativas, partindo de preocupações nem sempre coincidentes com as nossas - deparamo-nos, por vezes, com questões que permaneceram sem resposta, com lacunas de informação acerca da efetividade do conteúdo discutido e da continuidade dos projetos.

Aqui retomamos um problema identificado logo no início do processo de investigação, isto é, o tênue limite entre prevenção e promoção quando diante da implementação de práticas e políticas do setor Saúde. No presente trabalho, a orientação pelo referencial da chamada "nova promoção de saúde" (Labonte, 1996a) e pelos sete princípios assumidos pela OMS (WHO, 1998), viabilizou a investigação e esclareceu-nos sobre a distinção entre promoção, prevenção $e$ medidas assistenciais.

Como já mencionado, a "nova promoção de saúde" se propõe a enfocar os determinantes gerais, isto é, os sócio-ambientais e econômicos, atuando sobre as condições de vida cotidianas e sendo direcionada ao coletivo e à defesa dos direitos sociais. Trata-se, portanto, de um processo de fomento ao compromisso político (dos gestores e sociedade civil) e de impulsão às mudanças sociais. Vale aqui resgatar a concepção de Cohn (2000), que afirma que promover saúde hoje é combater a naturalização da pobreza e forçar para que as questões sociais sejam remetidas para o tema da desigualdade social. No atual contexto de crescente desemprego, desregulamentação do trabalho, quebra dos velhos contratos, flexibilização de direitos historicamente conquistados e submissão da gestão e gerência dos serviços públicos estatais à racionalidade do mercado, a participação, a cidadania e a promoção da saúde teriam sobretudo a atribuição de "reconstruir a esfera pública".

Ao buscarmos estabelecer um diálogo entre as definições de cada princípio e as cinco experiências-caso (considerando as particularidades de cada iniciativa $e$ seu contexto), ficaram evidentes as diferentes extensões da operacionalização de cada um dos princípios nos projetos. Parece-nos que as dificuldades para identificar a operacionalização do empoderamento e da intersetorialidade no interior dos relatos está ligada à maior dificuldade de colocar tais princípios em prática. Além disso, a investigação realizada nos permite sugerir que os sete princípios tenham distinta relevância para a viabilização da promoção de saúde. As ações multi-estratégicas parecem remeter mais a um princípio operativo e, como vimos, acabam sendo "naturalmente" contempladas quando a proposta é trabalhar com problemas e determinantes de ordem geral. Mais do que um princípio orientador da prática, a concepção holística (conforme aqui definida) nos parece o pressuposto inicial de qualquer ação voltada à nova promoção $e$ demonstrou ser importante para distinguir experiências voltadas à promoção daquelas com enfoque curativo-preventivo. Por sua vez, a participação social parece-nos o mais essencial dos princípios e deve ser cuidadosamente assegurada, principalmente no que tange ao poder deliberativo das instâncias de representação da sociedade civil. A intersetorialidade, apesar das resistências e lacunas, deve também merecer maior destaque, à medida que é essencial para viabilizar ações que de fato modifiquem as condições de vida cotidianas. A 
orientação pelo princípio da eqüidade é também premente, em função do contexto de desigualdade e injustiça social instalado. Por fim, a sustentabilidade coloca-se como princípio básico para assegurar a promoção na perspectiva da continuidade das políticas públicas.

A discussão aqui conduzida nos permite dizer que os princípios da promoção de saúde são suficientemente universalizáveis e operacionalizáveis a ponto de podermos encontrá-los em iniciativas de natureza diversa, nas quais, contudo, não havia em geral uma intencionalidade de serem orientadas por tais princípios ou pela concepção de promoção. Ainda mais importante para o campo da Saúde Coletiva talvez seja reconhecer que em nenhuma das experiências estudadas o setor Saúde foi o alavancador ou determinante do processo, tendo apenas um papel "coadjuvante", secundário; sua participação ficou restrita à assistência (expansão da rede) ou a ações educativo-preventivas - estas insuficientemente detalhadas para permitir esclarecimentos sobre seu conteúdo, método empregado e impacto alcançado.

Este ponto talvez mereça especial atenção, remetendo-nos a uma discussão maior que tangencia os resultados apresentados. Para além das necessidades dos projetos de promoção de Saúde extrapolarem o setor Saúde, ponto já de consenso entre os pesquisadores que hoje discutem a temática, a discussão aqui desenvolvida sugere que a operacionalização dos princípios da nova "promoção de Saúde" pode ser assgurada mesmo quando o setor não é central ou encabeçador do processo.

Recolocamo-nos, então, a seguinte indagação: que papel caberia ao setor Saúde numa política de promoção como a aqui concebida? Para além da assistência e cura, como historicamente delegado e ainda hegemônico entre atores e gestores da área, que atribuição poderia assumir no sentido de melhorar efetivamente as condições de vida cotidianas da população?

Reconhecendo a herança histórica do setor sanitário, assim como a desigual disputa de poder entre a assistência hospitalar $e$ a ambulatorial, a prevenção $e$ a promoção, $e$ ainda a necessidade de responder às prementes demandas assistenciais, podemos questionar a capacidade de o setor Saúde avançar além da assistência e prevenção. As ações de âmbito coletivo e que incidem sobre os determinantes sócio-econômicos e ambientais ficariam relegadas para um segundo momento, sendo dificilmente contempladas. Contudo, é possível defender que, pelo fato de debruçar-se sobre a situação de saúde (um "problema-fim", que está na ponta do processo e reflete as lacunas e carências deixadas por precárias condições de vida), o setor Saúde teria maior potencial do que outros do poder público para indicar as ações necessárias à promoção, mesmo que sua execução coubesse a setores afins, como saneamento, habitação, educação, assistência social etc. O setor Saúde poderia ter, além das atribuições "tradicionais", um papel de destaque para a operacionalização da intersetorialidade, sensibilizando outros setores e viabilizando a pactuação de metas e objetivos comuns, voltados a impactar positivamente sobre as condições de vida cotidianas e seus determinantes sócio-econômicos e ambientais.

Que papel caberia, então, ao setor Saúde numa política de promoção como a aqui concebida? Para além da assistência e cura, como historicamente delegado $e$ ainda hegemônico entre atores e gestores da área, que atribuição poderia 
assumir no sentido de melhorar efetivamente as condições de vida cotidianas da população? Resgatando nosso anseio pragmático, como encontrar experiências que demonstrem a concretização deste potencial?

Para responder satisfatoriamente a tais indagação é necessário um novo desenho de pesquisa que, assumindo o referencial da promoção de saúde e seus princípios tal como aqui desenvolvidos, ocupe-se de experiências nas quais o setor Saúde tenha papel de destaque, sendo reconhecidamente encabeçador ou central para o processo, especialmente quanto à intersetorialidade.

\section{Referências}

BRASIL. Constituição (1988). Constituição da República Federativa do Brasil - Título VIII, Capítulo II, Seção II. Brasília: Senado, 1988.

BRASIL. Ministério da Saúde. Promoção da Saúde: Declaração de Alma-Ata, Carta de Otawa, Declaração de Adelaide, Declaração de Sundsvall, Declaração de Santafé de Bogotá, Declaração de Jacarta, Rede de Megapaíses e Declaração do México. Brasília, 2001.

CARVALHO, M. C. A. A., FELGUEIRAS, D. Orçamento participativo no ABC: Mauá, Ribeirão Pires e Santo André. São Paulo: Polis, 2000.

CERQUEIRA, M T. Promoción de la salud y educación para la salud: retos y perspectivas. In: ORGANIZACIÓN MUNDIAL DE LA SALUD. La promoción de la salud y la educación para la salud en América Latina: un análisis sectorial. Genebra: Editorial de La Universidad de Puerto Rico, 1997. p.7-48.

COHN, A. Participação e cidadania na promoção da saúde. In: CONGRESSO PAULISTA DE SAÚDE PÚBLICA, 6., 1999, Águas de Lindóia. Anais... São Paulo: APSP, 2000. v.2, p.297-301.

EAESP/FGV. Programa Gestão Pública e Cidadania. Disponível em <http://www.gv.br/ford/ gpcindex.asp>. acesso em 29 jan. 2001.

FUNDAÇÃO OSWALDO CRUZ. Promoção de saúde e qualidade de vida. Tema: Cidades Saudáveis. Radis, n.19, p.12-3, 2000.

HADDAD, S. Participação e cidadania na promoção da saúde. In: CONGRESSO PAULISTA DE SAÚDE PÚBLICA, 6, 1999. Águas de Lindóia. Anais.... São Paulo: APSP, v.2, 2000. p.281-5.

JACOBI, P. Poder local, políticas sociais e sustentabilidade. Saúde e Sociedade, v.8, n.3, p.31-48, 1999.

JUNQUEIRA, L. A. P., INOJOSA, R. M. Desenvolvimento social e intersetorialidade na gestão pública municipal. Brasília: Ministério da Saúde, 2001. Disponível em <http://www.datasus.gov.br/cns/ cns.htm>. acesso em 26 nov. 2001.

JUNQUEIRA, R. G. P. A intersetorialidade do ponto de vista da educação ambiental: um estudo de caso. Rev. Adm. Pública, v.32, n.2, p.79-91, 1998.

LABONTE, R. Estrategias para la promoción de la salud en la comunidad. In: ORGANIZACIÓN PANAMERICANA DE LA SALUD. Promoción de la salud: uma antología. Washington: OPAS, 1996, p.153-65. (Publicación científica, 557).

LABONTE, R. Community empowerment and leisure. J. Leisurability, v.23, n.1, 1996b. Disponível em <http://www.lin.ca/resource/html/Vol23/v23n1a2.htm>. acesso em 02 mar. 2001.

MELLO, D. A. Reflexões sobre a promoção de saúde no contexto do Brasil. Cad. Saúde Pública, v.16, n.4, p.1149, 2000.

MELLO, D A., ROUQUAYROL, M.Z., ARAÚJO, D., AMADEI, M., SOUZA, J., BENTO, L.F., GONDIN, J., NASCIMENTO, J. Promoção à saúde e educação: diagnóstico de saneamento através da pesquisa participante articulada à educação popular (Distrito São João dos Queiróz, Quixadá, Ceará, Brasil). Cad. Saúde Pública, v.14, n.3, p.583-95, 1998.

ORGANIZACIÓN MUNDIAL DE LA SALUD. Carta de Ottawa para la promoción de la salud. In: ORGANIZACIÓN PANAMERICANA DE LA SALUD. Promoción de la salud: uma antologia. Washington: OPAS, 1996. p.367-72.

PEREIRA, I. M. T. B., PENTEADO, R. Z., MARCELO, V. C. Promoção de saúde e educação em saúde: uma parceria saudável. O mundo da saúde, ano 24, v.24, n.1, p.39-44, 2000.

PRATA, P. R. Desenvolvimento econômico, desigualdade e saúde. Cad. Saúde Pública, v.10, n.3, p.387- 
SÍCOLI, J. L., NASCIMENTO, P. R.

91, 1994.

TERRIS, M. Conceptos de la promoción de la salud: dualidades de la teoría de la salud publica. In: ORGANIZACIÓN PANAMERICANA DE LA SALUD. Promoción de la salud: una antología. Washington: OPAS, 1992, p.37-44. (Publicación científica, 557).

WESTPHAL, M. F., ZIGLIO, E. Políticas públicas e Investimentos: a Intersetorialidade. In: CENTRO DE ESTUDOS E PESQUISAS DE ADMINISTRAÇÃO MUNICIPAL. O município e o século XXI: cenários e perspectivas. São Paulo: CEPAM, s/d.

WHITEHEAD, M. Conceptos y principios de la igualdad y salud. Copenhague: OMS, Oficina Regional para Europa, 1990.

WORLD HEALTH ORGANIZATION. Discussion document on the concept and principles. In: Health promotion: concepts and principles, a selection of papers presented at Working Group on Concepts and Principles. Copenhagen: Regional Office for Europe, 1984. p.20-3.

WORLD HEALTH ORGANIZATION. Health promotion evaluation: recommendations to policymakers. Copenhagen: European Working Group on Health Promotion Evaluation, 1998.

ZIGLIO, E., HAGARD, S., MCMAHON, L., HARVEY, S., LEVIN, L. Inversión en favor de la salud. In: CONFERÊNCIA MUNDIAL DE PROMOCIÓN DE LA SALUD, 5, 2000, México. Informe técnico... México, 2000. Disponível em <http://www.who.int/hpr/conference/products/Techreports/spanishdocs/invest-fn> acesso em 20 nov. 2001.

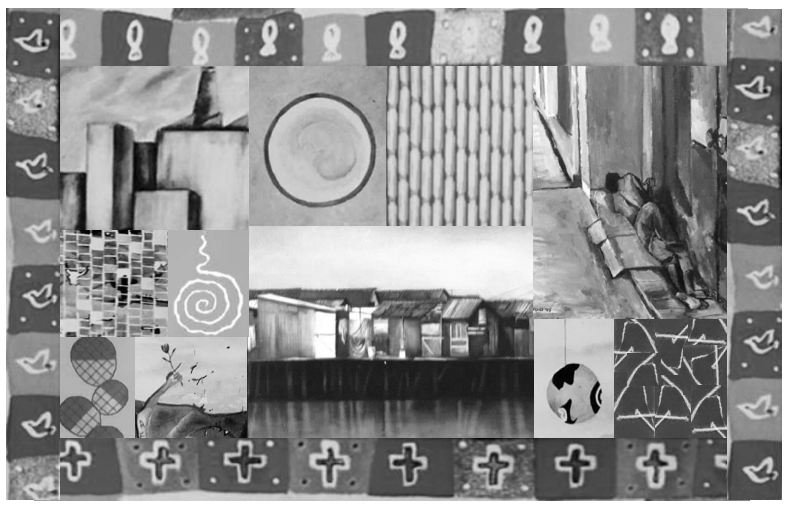

SÍCOLI, J. L., NASCIMENTO, P. R. Promoción de la salud: concepciones, principios y operacionalización, Interface - Comunic, Saúde, Educ, v.7, n.12, p.91-112, 2003.

A partir del relevamiento bibliográfico acerca de los antecedentes, concepciones y practicas de la promoción de salud, identificamos la laguna existente en su dimensión metodológica, o sea, escasas experiencias que demuestren coherencia respecto al discurso de la promoción. El objetivo del estudio fue, entonces, describir la posible operacionalización de los siete principios que configuran las iniciativas en promoción de salud según la definición de la OMS (concepción holística, intersectorialidad, empoderamiento, participación social, equidad, acciones multiestratégicas y sustentabilidad). Con base en datos secundarios y análisis documental, evaluamos cinco acciones de gestión pública en distintos sectores, a partir del banco de datos del Programa Gestión Pública y Ciudadanía (EAPSP/FGV), identificando cada uno de los principios, sus límites, posibilidades y relevancia para la promoción. La investigación posibilitó concluir que los principios mencionados son suficientemente universalizables y operacionalizables, permitiendo su identificación en iniciativas de distintas naturalezas y en las que el sector salud no tuvo papel preponderante. Una posible cuestión para futuros estudios es buscar qué papel podría tener el sector salud en las políticas de promoción (según la concepción asumida en este estudio) para ejercer mayor impacto en las condiciones de vida cotidianas y los determinantes socioeconómicos y ambientales de la salud, según la llamada "nueva promoción de salud".

PALABRAS CLAVE: Promoción de la salud; gestión pública; participación social; acción intersectorial. 